\title{
Frailty among Older Adults and Its Distribution in England
}

DOI:

10.14283/jfa.2021.55

\section{Document Version}

Final published version

Link to publication record in Manchester Research Explorer

\section{Citation for published version (APA):}

Sinclair, D., Maharani, A., Chandola, T., Bower, P., Hanratty, B., Nazroo, J., O'Neill, T., Tampubolon, G., Todd, C., Wittenberg, R., Matthews, F., \& Pendleton, N. (2021). Frailty among Older Adults and Its Distribution in England. The Journal of Frailty \& Aging, 1-6. https://doi.org/10.14283/jfa.2021.55

\section{Published in:}

The Journal of Frailty \& Aging

\section{Citing this paper}

Please note that where the full-text provided on Manchester Research Explorer is the Author Accepted Manuscript or Proof version this may differ from the final Published version. If citing, it is advised that you check and use the publisher's definitive version.

\section{General rights}

Copyright and moral rights for the publications made accessible in the Research Explorer are retained by the authors and/or other copyright owners and it is a condition of accessing publications that users recognise and abide by the legal requirements associated with these rights.

\section{Takedown policy}

If you believe that this document breaches copyright please refer to the University of Manchester's Takedown Procedures [http://man.ac.uk/04Y6Bo] or contact uml.scholarlycommunications@manchester.ac.uk providing relevant details, so we can investigate your claim.

\section{OPEN ACCESS}




\title{
Frailty among Older Adults and Its Distribution in England
}

\author{
D.R. Sinclair ${ }^{1, *}$, A. Maharani ${ }^{2, *}$, T. Chandola ${ }^{3}$, P. Bower ${ }^{2}$, B. Hanratty ${ }^{\text {, J. Nazroo }}$, T.W. O’Neill ${ }^{2}$, \\ G. Tampubolon ${ }^{5}$, C. Todd ${ }^{2}$, R. Wittenberg ${ }^{6}$, F.E. Matthews ${ }^{1, *}$, N.Pendleton ${ }^{2, *}$
}

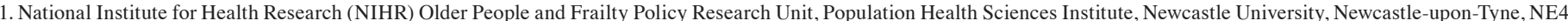

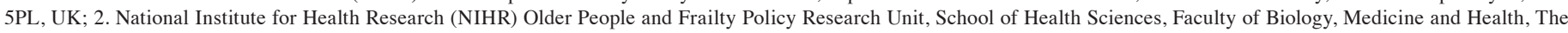

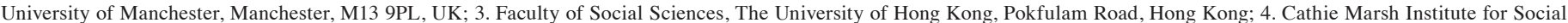

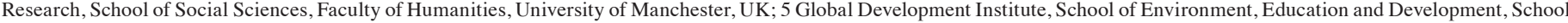

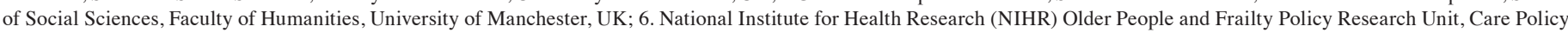
and Evaluation Centre, London School of Economics and Political Science, London, WC2A 2AE, UK. *these authors contributed equally to this work
\end{abstract}

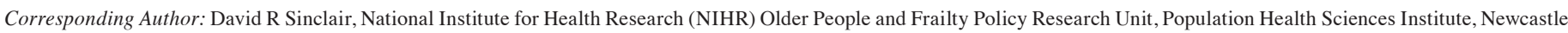
University, Newcastle-upon-Tyne, NE4 5PL, UK, Email address: David.R.Sinclair@newcastle.ac.uk

\begin{abstract}
BACKGROUND: Information on the spatial distribution of the frail population is crucial to inform service planning in health and social care. OBJECTIVES: To estimate small-area frailty prevalence among older adults using survey data. To assess whether prevalence differs between urban, rural, coastal and inland areas of England.

DESIGN: Using data from the English Longitudinal Study of Ageing (ELSA), ordinal logistic regression was used to predict the probability of frailty, according to age, sex and area deprivation. Probabilities were applied to demographic and economic information in 2020 population projections to estimate the district-level prevalence of frailty.

RESULTS: The prevalence of frailty in adults aged 50+ (2020) in England was estimated to be 8.1 [95\% CI 7.3-8.8]\%. We found substantial geographic variation, with the prevalence of frailty varying by a factor of 4.0 [3.5-4.4] between the most and least frail areas. A higher prevalence of frailty was found for urban than rural areas, and coastal than inland areas. There are widespread geographic inequalities in healthy ageing in England, with older people in urban and coastal areas disproportionately frail relative to those in rural and inland areas. CONCLUSIONS: Interventions aimed at reducing inequalities in healthy ageing should be targeted at urban and coastal areas, where the greatest benefit may be achieved.
\end{abstract}

Key words: Frailty, frailty index, ageing, health inequalities, rural.

\section{Introduction}

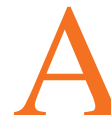

s the English population inexorably becomes older, frailty is becoming an increasingly abundant and demanding issue. Currently, almost one-in-five (18\%) people (over 12 million) are aged over 65 years (1). By 2038, this proportion will have risen to almost one-in-four (24\%) (2) suggesting a continuous increase in health and social care needs.

Primary care records suggest that, in 2016, approximately $3 \%$ of people aged 65 and over in England are living with frailty (3) almost half of these are over 80 (4). However, this may be an underestimate as medical records under-report disabilities (5). Frailty is associated with poor quality of life, adverse health outcomes, such as falls, and increased use of health and social care services (6-8), but research has shown that frailty is not an inevitable consequence of ageing (9). Preventing frailty is important to promote the health and wellbeing of older people and reduce their need for National Health Service (NHS) and social care, especially as the population ages.

Frailty has been described as a distinctive health state related to the ageing process, in which multiple body systems gradually lose their in-built reserves (10-12). There is no universal measurement of frailty and estimates of prevalence vary significantly (13). However, there are two operational definitions of frailty in common use, within which frailty estimates have lower variation (13): frailty phenotype and frailty index.

The frailty phenotype, proposed by Fried et al. (10), describes a group of individual characteristics (weakness, slowness, low level of physical activity, exhaustion, and unintentional weight loss) that predict poor outcomes. A person is judged to be frail if they have at least three of the five characteristics; pre-frail if they have one or two characteristics; and robust if they have none of the characteristics.

The frailty index, or cumulative deficit model, was developed by Mitnitski et al. (14). In this model, people accumulate 'deficits' over time that increase their risk of poor outcomes. Deficits range from conditions (such as dementia) to symptoms (e.g., hearing loss) and signs (e.g., tremor). The deficits measured vary between frailty indices, although all share a standard basis (15). The fraction of deficits present in an individual can indicate whether they are frail (3). Frailty indices have been shown to be associated with mortality, hospitalisation and nursing home admission $(3,16)$.

To prevent the development of frailty and provide care for people who are frail, policymakers and commissioners require information on population health needs. Our current understanding of the geographical distribution of frailty comes from two multinational studies $(17,18)$, and three from single countries (the USA (19), Australia (20), and China (21)). All but the Australian study use large geographical areas, such as countries or extensive regions, neglecting the effect of smallarea characteristics on older people's health.

In the past, frailty amongst people admitted to hospital 
has been mapped to English Primary Care Trust areas using surrogate diagnostic codes (22). This surrogate metric has contributed to maps of 'vulnerability' produced by the British Red Cross (23). However, frailty scores from surrogate diagnostic codes are not necessarily equivalent to those derived from standard frailty index measures. Furthermore, medical records may underestimate the prevalence of disabilities (5). To date, there have been no national, community-based studies on the distribution of frailty in England. All previous work has focused on the production of a single national or UK figure for frailty, due to the absence of estimates of frailty at a small area level.

Evidence suggests there are inequalities in the health of older people associated with geographic location in the UK. Studies have found higher rates of mortality and worse health among urban areas than rural $(24,25)$, although there are exceptions in remote rural areas of Scotland (26). The over 65 population is expected to increase by $50 \%$ in both urban and rural areas by 2039 , however the under 65 population is projected to grow by $8 \%$ in urban areas and not at all in rural areas (27).

On the other hand, a Public Health England review on health inequalities in ageing reported a paucity of literature focusing on coastal areas (28). This review further highlighted the need for small-area information, rather than national statistics which may overlook the differences between areas. Small-area data can aid community-based approaches to reducing health inequalities in older people.

This study aims to investigate the area-level distribution of frailty in England, using synthetic estimation to derive small-area profiles of frailty prevalence. It answers a series of research questions: are there disparities in frailty prevalence among areas in England; is the prevalence of frailty higher in urban than rural areas; and is the prevalence of frailty higher in coastal than inland areas? Understanding if, and where, differences in the prevalence of frailty exist will help health and care systems better target policies aimed at reducing inequalities in ageing. This study allows for the description of frailty to be undertaken across policy-relevant areas such as lower tier local authority districts.

\section{Methods}

\section{Data}

This study drew on three data sources for the analysis: (a) the English Longitudinal Study of Ageing (ELSA); (b) English Index of Multiple Deprivation (IMD) scores; and (c) 2020 Office for National Statistics population projections for local authorities.

ELSA is a prospective cohort study of approximately 18,000 adults aged 50 or older resident across England (29). ELSA collects information on demographic and socioeconomic characteristics, along with information on lifestyle, and health and social care use. ELSA uses a panel design, in which the same respondents are interviewed every two years, with new survey participants added in waves 3, 4, 6, 7 and 9 to adjust for ageing and attrition. In our analysis, we used the ELSA wave 8 sample (interviewed in 2016/2017); this is the latest wave for which deprivation scores (IMD) are available for participants' residential areas (at time of study). The wave 8 sample with deprivation scores comprised 8,355 individuals. Survey weights were used to adjust for non-response and to ensure population representativeness.

The 2019 IMD scores and 2020 population projections, by age and sex, for local authority districts were the sources of area-level data $(2,30)$. IMD is a measure of relative deprivation for small areas in England. It uses metrics of income, employment, education, health, crime, housing and the environment to create a score which ranks areas of England by their relative deprivation. IMD scores were categorised into quintiles, grouping broadly similar areas of deprivation together. IMD scores for the relative deprivation of each local authority district were obtained from the Ministry of Housing, Communities \& Local Government (30).

England is divided into 314 lower tier local authorities (as of April 2020) with populations typically ranging from 50-600 thousand. Each local authority's governing council is responsible for a range of services, including (for lower tier councils which also function as upper tier councils) social care. Forecast 2020 populations for each local authority district in England, split into sex and five-year age bands, were obtained from the Office for National Statistics (2). The list of variables at area level and their definitions are provided in Appendix 1a, with more detailed methods.

Local authority districts were categorised into urban or rural using the Office for National Statistic's 2011 rural-urban classification (31). All districts whose borders include foreshore (except within estuaries only) were categorised as coastal. Appendix 2 provides the categorisation of each local authority.

\section{Frailty definition}

Individual-level variables were taken from ELSA wave 8. A frailty index was constructed for each dataset, from variables (termed 'deficits') representing conditions that a) accumulate with age and b) are associated with adverse outcomes. Deficits included functional and sensory impairments, clinical diagnoses, and poor cognitive function. Higher frailty scores, calculated by the fraction of deficits present in an individual, indicate greater levels frailty.

The frailty index was generated following the procedure described by Wade and colleagues (32). Appendix 3 provides a list of variables included in the frailty index. The frailty index was divided into three categories: frail $(>0.36)$, pre-frail $(>0.24-$ $0.36)$ and robust $(\leq 0.24)(3)$. To simplify the paper the main manuscript concentrates on frail groups; the pre-frail results can be found in Appendix 3. The list of individual-level covariates (age, sex, and IMD score) and their definitions are provided in Appendix 1b. 
Table 1. Characteristics of ELSA wave 8 participants $(n=8,355) .600$ individuals had missing data on at least one of the 51 variables comprising the frailty index, hence the smaller number of individuals in the frailty categories. 44 individuals were missing an IMD (English Index of Multiple Deprivation) quintile. Individuals with missing data were included by undertaking multivariate imputation by chained equations (MICE)

\begin{tabular}{|c|c|c|c|}
\hline Variable & $\mathbf{n}$ & Percent (weighted) & Imputed percent \\
\hline \multicolumn{4}{|l|}{ Sex } \\
\hline Male & 3,727 & 47.5 & $47.5(46.0-49.1)$ \\
\hline Female & 4,628 & 52.5 & $52.5(50.9-54.0)$ \\
\hline \multicolumn{4}{|l|}{ Age } \\
\hline $50-54$ & 433 & 12.6 & $12.6(11.1-14.1)$ \\
\hline $55-59$ & 821 & 18.6 & $18.6(17.0-20.1)$ \\
\hline $60-64$ & 1,623 & 16.1 & $16.1(15.2-17.0)$ \\
\hline $65-69$ & 1,732 & 16.7 & $16.7(15.8-17.5)$ \\
\hline $70-74$ & 1,391 & 13.0 & $13.0(12.3-13.8)$ \\
\hline $75-79$ & 1,033 & 9.7 & $9.7(9.1-10.4)$ \\
\hline $80-84$ & 792 & 7.1 & $7.1(6.5-7.6)$ \\
\hline $85-89$ & 358 & 3.9 & $3.9(3.5-4.4)$ \\
\hline $90+$ & 172 & 2.3 & $2.3(1.9-2.7)$ \\
\hline \multicolumn{4}{|l|}{ IMD quintile } \\
\hline Most deprived & 993 & 14.1 & $14.1(13.0-15.3)$ \\
\hline 2 & 1.406 & 18.4 & $18.4(17.1-19.7)$ \\
\hline 3 & 1,730 & 20.6 & $20.6(19.4-21.8)$ \\
\hline 4 & 2,157 & 24.1 & $24.1(22.8-25.4)$ \\
\hline Least deprived & 2,025 & 22.9 & $22.9(21.6-24.1)$ \\
\hline (Missing) & $(44)$ & & \\
\hline \multicolumn{4}{|l|}{ Frailty category } \\
\hline Robust & 6,374 & 83.1 & $82.0(81.0-83.1)$ \\
\hline Pre-frail & 835 & 9.9 & $9.9(9.1-10.7)$ \\
\hline Frail & 546 & 7.1 & $8.0(7.3-8.8)$ \\
\hline (Missing) & $(600)$ & & \\
\hline
\end{tabular}

\section{Statistical analysis}

Small area estimation is a statistical method for generating estimates in small geographical areas that would otherwise not have enough representative samples to derive precise direct estimates (33). Predicted prevalence estimates of frailty were estimated from ELSA wave 8 for respondents aged 50+ years by age, sex and deprivation quintile using generalised ordered logistic regression (34) on the frail and robust categories. Fitting was conducted with Stata's gologit2 program (35). Inverse probability weighting was used to account for sampling and non-response (17.6\% in ELSA wave 8 (36)). Interactions between frailty, age and sex were not significant. Missing values in the frailty index variables were imputed using multiple imputation by chained equation (MICE) (37) with 40 imputation samples. Predicted estimates were mapped to age, sex and deprivation quintile for each area and the standardised estimate of frailty for each local authority district calculated. Appendix 4 describes the detailed method.

\section{Results}

Complete information for all deficits in the frailty index was available for 7,755 ELSA wave 8 participants, with 600 additional individuals with at least one missing variable on the frailty index variables included by undertaking multivariate imputation by chained equations (MICE). The imputation model included age, sex, and area deprivation quintile.

\section{Frailty prevalence}

The prevalence of frailty among people age $50+$ was 8.1 [95\% Confidence Interval 7.3-8.8]\%, respectively. The estimates was higher for women $(9.1$ [8.0-10.1]\%) than men $(6.8[5.9-7.8] \%)$. Table 2 indicates how sex-specific estimates of frailty varies with age. The generalised ordered logistic regression model shows positive associations between frailty and deprivation, age and female sex (Appendix 5). The prevalence of frailty increases steeply with advancing age. 
Table 2. Estimated frailty prevalence in 2020 by sex and age using ordered logistic regression model calculated from ELSA wave 8 data. $95 \%$ Confidence Intervals (CIs) given

\begin{tabular}{|l|c|c|c|}
\hline Age group & All $(\boldsymbol{\%}, \mathbf{C I})$ & Male $(\boldsymbol{\%}, \mathbf{C I})$ & Females $(\boldsymbol{\%}, \mathbf{C I})$ \\
\hline Frailty & & & \\
\hline $50-54$ & $2.8(0.8-4.7)$ & $2.3(0.6-4.0)$ & $3.2(1.0-5.4)$ \\
\hline $55-59$ & $4.3(2.3-6.3)$ & $3.6(2.0-5.2)$ & $4.9(2.5-7.3)$ \\
$60-64$ & $6.8(5.3-8.4)$ & $5.8(4.3-7.2)$ & $7.8(5.9-9.7)$ \\
$65-69$ & $6.0(4.7-7.3)$ & $5.0(3.7-6.3)$ & $6.9(5.3-8.4)$ \\
$70-74$ & $7.9(6.3-9.5)$ & $6.7(5.1-8.3)$ & $9.0(7.1-11.0)$ \\
$75-80$ & $10.0(7.9-12.1)$ & $8.5(6.4-10.5)$ & $11.4(8.9-13.9)$ \\
$80-84$ & $13.9(11.3-16.6)$ & $11.9(9.1-14.7)$ & $15.7(12.7-18.8)$ \\
$85-89$ & $22.9(18.1-27.7)$ & $20.0(15.0-25.0)$ & $25.5(20.4-30.7)$ \\
$90+$ & $40.8(32.3-49.4)$ & $36.9(28.0-45.8)$ & $44.4(35.5-53.3)$ \\
\hline $50+$ & $8.1(7.3-8.8)$ & $6.8(5.9-7.8)$ & $9.1(8.0-10.1)$ \\
\hline
\end{tabular}

\section{Geographical differences}

Substantial area variations are found in the frailty estimates. The prevalence among people age 50 and over in rural, urban, inland and coastal areas are plotted in Figure 1 (numbers included in Appendix 6). The highest median prevalence rates of frailty are found in urban (7.3 [6.5-8.2]\%) and coastal (8.9 $[7.9-9.9] \%)$ areas, while rural $(4.8[4.3-5.3] \%)$ and inland $(6.7[6.2-7.1] \%)$ areas have the lowest. Outlying data points in Figure 1 are associated with local authorities in the highest deprivation quintile.

Figure 1. Prevalence of frailty among over 50s in among different local authority district area types

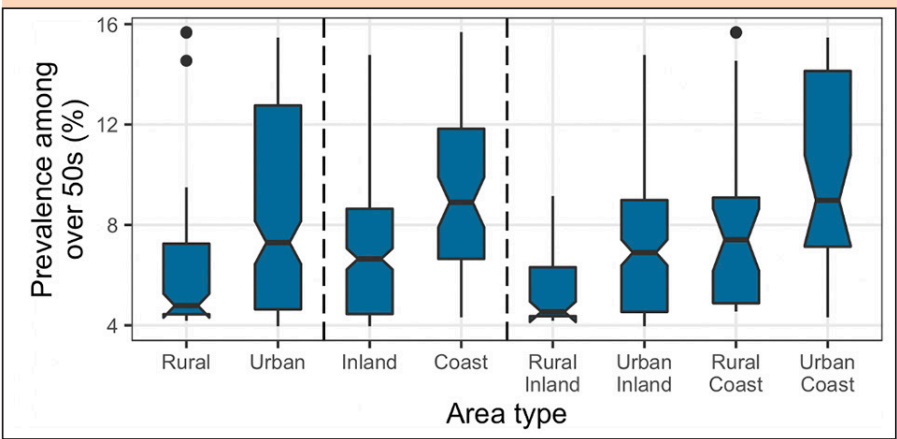

All local authority districts are categorised as either rural or urban, and either inland or coastal. Rural-inland shows areas that are both rural and inland; similarly for urban-inland, rural-coast and urban-coast. Boxes indicate the 25 th to 75 th percentiles, notches the uncertainty on the median, and whiskers the largest/smallest value no further than 1.5 times the interquartile range above/below each box. Dots indicate outliers from the whiskers. See Appendix $3 b$ for pre-frailty prevalence.

The risk ratio of frailty in coastal areas relative to inland areas is 1.3 [1.2-1.5] (Figure 2), while urban areas have a risk ratio of frailty relative to rural areas of 1.5 [1.3-1.8].

Areas which are both rural and inland have lower frailty prevalence (4.5 [4.1-5.0]\%) than urban-inland (6.9 [6.4-7.4]\%), rural-coastal $(7.4[6.2-8.6] \%)$ and urban-coastal (9.0 [7.2$10.8] \%$ ) areas (Figure 1).

The frailty estimate for each local authority district is mapped in Figure 3 (all area prevalence estimates, along with pre-frailty and male and female-only estimates, are provided in Appendixes 7 and 8). High estimates of frailty are clustered in northern areas and the West Midlands. However, the highest estimates are predominantly found in coastal areas, such as East Lindsay (Lincolnshire), Tendring (Essex), and Great Yarmouth (Norfolk), where frailty prevalence are both estimated to exceed $15 \%$ of over $50 \mathrm{~s}$. The lowest estimates $(<2.9 \%$ frailty of over 50s) are found in rural areas and suburbs of the capital (London), including Bracknell Forest (Berkshire), Richmond upon Thames (London) and Kingston upon Thames (London).

Figure 2. Risk ratio of frailty in (left) urban, relative to rural and (right) in coastal, relative to inland, local authority districts

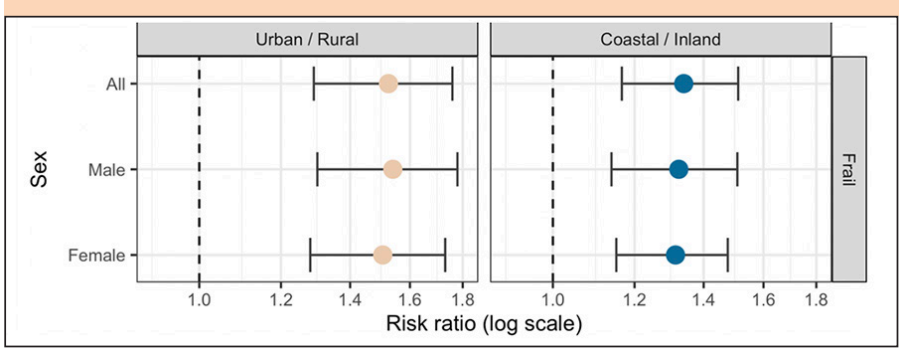

Risk ratios are calculated using median prevalence of local authority districts in each area type. See Appendix $3 \mathrm{c}$ for pre-frailty risk ratios.

Figure 3. Estimated prevalence of frailty among people aged over 50 in each local authority district in England, 2020

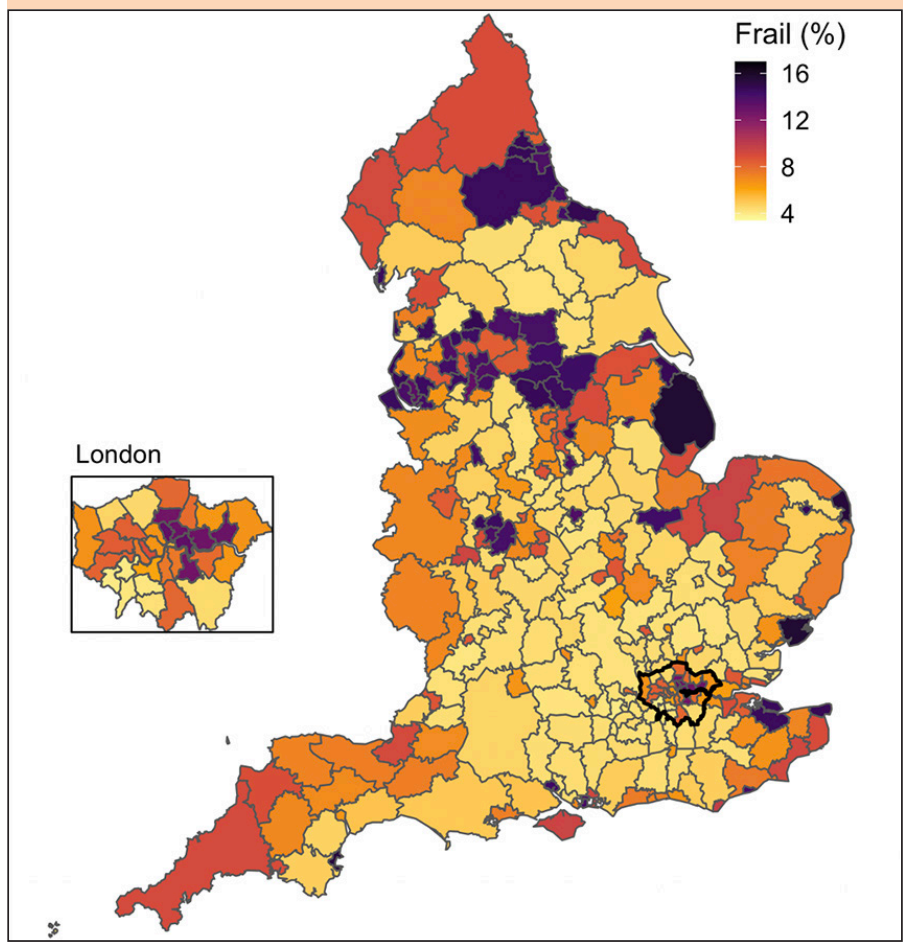

Among local authorities, the lowest frailty prevalence of people aged 50 and over is 4.0 [3.5-4.5]\%, and the highest is $15.7[14.6-16.8] \%$, a factor of 4.0 [3.5-4.4] difference.

\section{Discussion}

This study is among the first to produce small area estimates for frailty prevalence in England and has found differences in frailty prevalence between urban and rural areas, as well 
as between coastal and inland areas. We estimated that the prevalence of frailty among adults aged 50+ in England in 2020 was $8.1 \%$. There are widespread geographic inequalities in healthy ageing, with the greatest frailty prevalence in coastal areas. This suggests policies aimed at reducing inequalities in healthy ageing should be targeted at coastal areas, as this is where the greatest benefit may be achieved.

Deprivation is strongly associated with frailty prevalence. Proportionally, urban and coastal areas are more deprived than rural and inland areas (Appendix 9), offering an explanation for the greater frailty levels in these areas.

Our estimation of national frailty prevalence is higher than two previous studies of over $65 \mathrm{~s}$ in the UK using the electronic Frailty Index (eFI), which estimated $3 \%$ frailty prevalence (35). The lower frailty estimates may arise from differences in eFI data and the ELSA survey data: eFI is based on medical records, which may under-report disabilities (5). If medical records do not capture the number of distinct frailty deficits in the frailest people, this may partially explain why our survey-based study finds more frailty. The eFI also has greater weighting on diseases and less on mobility, activities of daily living and instrumental activities of daily living than the frailty index used here, which may lead to higher frailty index scores here.

A previous study assessing phenotypic frailty using ELSA wave 4 (2008-09) found a national prevalence of frailty among over 60 s to be $14 \%$ (38); however frailty phenotype is a complimentary measure to a frailty index, with results that are not directly comparable (13). We therefore cannot compare whether frailty prevalence has changed over time with this study.

Another previous study, which used diagnosis codes as a surrogate for frailty, estimated the geographic heterogeneity of frailty prevalence to be consistent with the distribution of the older adult population and location of NHS acute provider sites (22). Our study suggests that urban and coastal areas have a disproportionately high frailty burden among the over 50 population.

One plausible explanation for the differences in frailty prevalence between area types is the internal migration of older people in England. Migration trends show that older people move mainly to coastal and rural locations (39).

Our study does not specifically evaluate the health status of movers. However, if the 'healthy migrant' effect (40) applies to these intra-national moves, we would expect migration to improve the average health of the older population in rural and coastal areas. Our results suggest this is only partially true: older populations in coastal areas are significantly frailer than those in rural areas. This is likely to be associated with area deprivation. Coastal areas are typically more deprived than rural areas (Appendix 9), and area-level deprivation may influence which areas older people move to: people who live in less deprived areas (and thus likely more healthy (41)) may be more likely to move to less deprived areas. This may lead to older people in deprived areas preferentially moving to disadvantaged coastal areas.

While these results find higher levels of frailty in urban than rural areas of England, this may not be the case elsewhere. Australian (20) and Canadian studies (42) found a greater prevalence of frailty in rural areas. Differences in the demographic and socioeconomic characteristics of people living in rural and urban areas between countries may contribute to these contrasting findings.

The key strength of this study is that it provides comparable frailty estimates for all local authority districts across England using a large, nationally representative survey on ageing health in England. This helps fill the need for small-area information identified by Public Health England to help address inequalities in ageing (28). The availability of geographically linked deprivation data in ELSA allowed us to use area-based socioeconomic measures in our analysis, an important characteristic in predicting frailty among older adults in England (43).

There are several issues to consider when interpreting the results. First, it is important to acknowledge that the prevalence of frailty in this study is based on synthetic estimates that consider local demography and social-economic context. Other factors that predict frailty, such as health behaviours, may be included in future work. Second, we note that ELSA wave 8 has a limited number of respondents in the 90+ age category: 172. Inverse probability weights were used for each survey to minimise bias in the analysis. Finally, our estimates are based on future population estimates produced by the Office for National Statistics [2]; differences between these estimates and actual population numbers will affect the accuracy of these results.

We have described distinctive geographical variations in frailty prevalence among local authorities in England. Areas with high prevalence of frailty could be targeted to prevent or delay the development of frailty among their robust and prefrail populations. Actions might include physical activity and nutritional interventions (44). Future research could describe frailty prevalence using boundaries for more recently defined areas, such as Integrated Care Systems, and map areas where levels of frailty are high, but receipt of care is low, to identify foci of unmet need. This study could be replicated using data for other countries to understand the commonalities and differences in the geographical distribution of frailty between countries.

Financial Disclosure: This report presents independent research funded by the National Institute for Health Research Policy Research Unit in Older People and Frailty. The views expressed are those of the authors and not necessarily those of the NIHR or the Department of Health and Social Care. Policy Research Unit Programme Reference Number PR-PRU-1217-21502.

Ethics approval: Ethical approval for all the ELSA waves was granted from NHS Research Ethics Committees under the National Research and Ethics Service (NRES).

Acknowledgement: We thank both our academic and professional support colleagues from National Institute for Health Research Policy Research Unit in Older People and Frailty with whom we discussed the ideas presented in this paper during unit meetings.

Open Access: This article is distributed under the terms of the Creative Commons Attribution 4.0 International License (http://creativecommons.org/licenses/by/4.0/), which permits use, duplication, adaptation, distribution and reproduction in any medium or format, as long as you give appropriate credit to the original author(s) and the source, provide a link to the Creative Commons license and indicate if changes were made. 


\section{References}

1. Office for National Statistics, Estimates of the population for the UK, England and Wales, Scotland and Northern Ireland, mid-2018 based, 2018. https://www.ons.gov. uk/peoplepopulationandcommunity/ populationandmigration/populationestimates/ bulletins/annualmidyear populationestimates/mid2018.

2. Nash, A., Subnational population projections for England: 2016-based. 2018, Office for National Statistics: UK. https://www.ons.gov.uk/ peoplepopulationandcommunity/populationandmigration/populationprojections/ bulletins/subnationalpopulationprojectionsfor england/2016based

3. Clegg, A., et al., Development and validation of an electronic frailty index using routine primary care electronic health record data. Age Ageing, 2016. 45(3): p. 353360. doi: 10.1093/ageing/afx001.

4. National Institute for Health Research, Comprehensive Care - Older People Living with Frailty in Hospital. NIHR Themed Review: Comprehensive Care, 2017 (December). doi: 10.3310/themedreview-002370

5. Bogardus Jr, S.T., et al., What does the medical record reveal about functional status? A comparison of medical record and interview data. J Gen Intern Med, 2001. 16(11): p. 728-736. doi: 10.1111/j.1525-1497.2001.00625.x.

6. Hajek, A., et al., Frailty and healthcare costs-longitudinal results of a prospective cohort study. Age Ageing, 2018. 47(2): p. 233-241. doi: 10.1093/ageing/afx157

7. Ensrud, K.E., et al., Frailty and risk of falls, fracture, and mortality in older women: the study of osteoporotic fractures. J Gerontol A Biol Sci Med Sci, 2007. 62(7): p 744-751. doi: 10.1093/gerona/62.7.744.

8. Armstrong, J.J., et al., Examining three frailty conceptualizations in their ability to predict negative outcomes for home-care clients. Age Ageing 2010. 39(6): p. 755758. doi: 10.1093/ageing/afq121

9. Thompson, M.Q., et al., Frailty state transitions and associated factors in South Australian older adults. Geriatr Gerontol Int, 2018. 18(11): p. 1549-1555. doi 10.1111/ggi.13522.

10. Fried, L.P., et al., Frailty in older adults: evidence for a phenotype. J Gerontol A Biol Sci Med Sci, 2001. 56(3): p. M146-M157. doi: 10.1093/gerona/56.3.m146.

11. British Geriatrics Society, Royal College of General Practitioners, and Age UK, Fit for Frailty Part 1: Consensus best practice guidance for the care of older people living in community and outpatient settings. 2014, London: British Geriatrics Society.

12. British Geriatrics Society, Royal College of General Practitioners, and Age UK, Fit for Frailty Part 2: Developing, commissioning and managing services for people living with frailty in community settings. 2015, London: British Geriatrics Society.

13. Collard, R.M., et al., Prevalence of frailty in community-dwelling older persons: A systematic review. J Am Geriatr Soc 2012, John Wiley \& Sons, Ltd. p. 1487-1492. doi: 10.1111/j.1532-5415.2012.04054.x.

14. Mitnitski, A.B., A.J. Mogilner, and K. Rockwood, Accumulation of deficits as a proxy measure of aging. ScientificWorldJournal, 2001. 1, p. 323-336. doi: 10.1100/ tsw. 2001.58

15. Searle, S.D., et al., A standard procedure for creating a frailty index. BMC Geriatr, 2008. 8: p. 1-10. doi: 10.1186/1471-2318-8-24.

16. Kojima, G., S. Iliffe, and K. Walters, Frailty index as a predictor of mortality: systematic review and meta-analysis. Age Ageing, 2018. 47(2): p. 193-200. doi: 10.1093/ageing/afx 162

17. Santos-Eggimann, B., et al., Prevalence of frailty in middle-aged and older community-dwelling Europeans living in 10 countries. J Gerontol A Biol Sci Med Sci, 2009. 64(6): p. 675-681. doi: 10.1093/gerona/glp012

18. Tom, S.E., et al., Frailty and fracture, disability, and falls: a multiple country study from the global longitudinal study of osteoporosis in women. J Am Geriatr Soc, 2013. 61(3): p. 327-334. doi: 10.1111/jgs.12146

19. Bandeen-Roche, K., et al., Frailty in older adults: a nationally representative profile in the United States. J Gerontol A Biol Sci Med Sci, 2015. 70(11): p. 1427-1434. doi: 10.1093/gerona/glv133

20. Taylor, D., et al., Geospatial modelling of the prevalence and changing distribution of frailty in Australia-2011 to 2027. Exp Gerontol, 2019. 123: p. 57-65. doi: 10.1016/j. exger.2019.05.010

21. Wu, C., et al., Prevalence and correlates of frailty among community-dwelling Chinese older adults: the China Health and Retirement Longitudinal Study. J Gerontol A Biol Sci Med Sci, 2018. 73(1): p. 102-108. doi: 10.1093/gerona/glx098

22. Soong, J., et al., Quantifying the prevalence of frailty in English hospitals. BMJ Open, 2015. 5(10): p. e008456. doi: 10.1136/bmjopen-2015-008456.
23. British Red Cross. British Red Cross Covid-19 Vulnerability Index. 2020; Available from: https://britishredcrosssociety.github.io/covid-19-vulnerability/.

24. Jones, N.R. and I.R. Lake, The combined impact of rural residence and socioeconomic status on premature mortality. Health Place, 2013. 24: p. 90-96. doi: 10.1016/j.healthplace.2013.08.010.

25. Teckle, P., P. Hannaford, and M. Sutton, Is the health of people living in rural areas different from those in cities? Evidence from routine data linked with the Scottish Health Survey. BMC Health Serv Res , 2012. 12(1): p. 43. doi: 10.1186/1472-6963 $12-43$.

26. Levin, K.A. and A.H. Leyland, A comparison of health inequalities in urban and rural Scotland. Soc Sci Med, 2006. 62(6): p. 1457-1464. doi: 10.1016/j. socscimed 2005.08 .045

27. Office for National Statistics, Living longer: how our population is changing and why it matters. 2018: Available from https://www.ons.gov.uk/ peoplepopulationandcommunity/birthsdeathsandmarriages/ageing/articles/ livinglongerhowourpopulation ischangingand why itmatters/ 2018-08-13.

28. Haighton, C., S. Dalkin, and K. Brittain, An evidence summary of health inequalities in older populations in coastal and rural areas. 2019, Public Health England: London.

29. Nazroo, J., et al., English Longitudinal Study of Ageing: Waves 0-9, 1998-2019. [data collection]. In: Service UD, editor. 32 ed2020. 2020.

30. Office for National Statistics. English indices of deprivation 2019. 2019; Available from: https://www.gov.uk/government/statistics/english-indices-of-deprivation-2019. doi: 10.5255/UKDA-SN-5050-24

31. Bibby, P. and P. Brindley. 2011 Rural-Urban Classification of Local Authority Districts and Similar Geographic Units in England: A User Guide. 2017. Available from: https://www.gov.uk/government/statistics/2011-rural-urban-classification-oflocal-authority-and-other-higher-level-geographies-for-statistical-purposes.

32. Wade, K.F., et al., Does Pain Predict Frailty in Older Men and Women? Findings From the English Longitudinal Study of Ageing (ELSA). J Gerontol A Biol Sci Med Sci, 2017. 72(3): p. 403-409. doi: 10.1093/gerona/glw226.

33. Longford, N.T., Missing data and small-area estimation: Modern analytical equipment for the survey statistician. 2006: Springer Science \& Business Media. https://doi.org/10.1007/1-84628-195-4

34. Williams, R., Generalized ordered logit/partial proportional odds models for ordinal dependent variables. SJ, 2006. 6(1): p. 58-82. https://doi org/10.1177/1536867X0600600104

35. Reeves, D., et al., The challenge of ageing populations and patient frailty: Can primary care adapt? BMJ, 2018. 362: p. 1-7. doi: 10.1136/bmj.k3349.

36. Banks, J., et al., The Dynamics of Ageing: Evidence from the English Longitudinal Study of Ageing 2002-16 (Wave 8). 2018. Available from https://ifs.org.uk/ publications/13510. 10.1920/re.ifs.2019.0000

37. Azur, M.J., et al., Multiple imputation by chained equations: what is it and how does it work? International Journal of Methods in Psychiatric Research, 2011. 20(1): p. 40-49. doi: $10.1002 / \mathrm{mpr} .329$

38. Gale, C.R., C. Cooper, and A. Aihie Sayer, Prevalence of frailty and disability: findings from the English Longitudinal Study of Ageing. Age Ageing, 2015. 44(1): p. 162-165. doi: 10.1093/ageing/afu148

39. Office for National Statistics, Living longer: trends in subnational ageing across the UK. 2020, Office for National Statistics: London.

40. Razum, O., Migrant Mortality, Healthy Migrant Effect, in Encyclopedia of Public Health, W. Kirch, Editor. 2008, Springer Netherlands: Dordrecht. p. 932-935. https:// doi.org/10.1007/978-1-4020-5614-7_2188

41. Pickett, K.E. and M. Pearl, Multilevel analyses of neighbourhood socioeconomic context and health outcomes: a critical review. J Epidemiol Community Health, 2001. 55(2): p. 111-122. doi: 10.1136/jech.55.2.111.

42. Song, X., et al., Frailty and survival of rural and urban seniors: results from the Canadian Study of Health and Aging. Aging Clin Exp Res, 2007. 19(2): p. 145-153. doi: $10.1007 / \mathrm{BF} 0332468$

43. Lang, I.A., et al., Neighborhood deprivation, individual socioeconomic status, and frailty in older adults. J Am Geriatr Soc, 2009. 57(10): p. 1776-1780. doi: 10.1111/j.1532-5415.2009.02480.x.

44. Woolford, S., et al., Approaches to the diagnosis and prevention of frailty. Aging Clin Exp Res, 2020. doi: 10.1007/s40520-020-01559-3

How to cite this article: D.R. Sinclair, A. Maharani, T. Chandola, et al. Frailty among Older Adults and Its Distribution in England. J Frailty Aging 2021; http://dx.doi. org/10.14283/jfa.2021.55 